origin of the substance, nothing more; "carbamide" is suggestive of a particular structure, of a view which, so long as I can remember, has not been in accordance with the facts and is now, I suppose, fairly generally abandoned, though the error is still perpetuated in the text-books-but one of the main purposes text-books serve is the perpetuation of error. Other cases might be quoted; time was when "constitutions" were settled on paper and not a few names are survivals of the practice.

In a course of Cantor lectures on "Food Problems" which I gave in May, I9I9, I suggested the use of the term "advitant" in place of "vitamine." A word of good clang, its meaning is clear and will be obvious to most; the substances it is intended to cover are necessary to life and we may as well say so, though we have not the faintest idea what they are.

Henry F. Armstrong.

\section{Relativity and the Velocity of Light.}

Mr. Bartrum's excellent letter on p. 42 of Natcre of March Io has done good service in extracting an explanation from Dr. Jeans, but the latter ivill forgive my saying that his position is not clear yet, at least not clear to me. Briefly thus :

(a) If we are able to compare the velocities of tivo single light journeys, one of which may be under normal conditions and therefore known, surely we have determined the other.

(b) I cannot see that Majorana's interesting experiments prove more than that the propagation of light has the characteristics of wave, and not projectile, motion.

(c) I admit Dr. Jeans's equations (1), (2), and (3), but I can see no merit in afterwatds introducing $v$. If they are true for all reasonable values of $u$, what more is gained by writing $u+v$ instead of $u$ ? Are they not the same thing?

Oliver Lodge.

\section{The Peltier Effect and Low-temperature Research.}

From certain considerations emphasised by me in the Phil. Mag. for December (Supplement), 1876 , especially $\S 33$, ser. v., vol. ii., p. 538 , about true contact e.m.f., I concluded that such forces are intimately connected with electrical resistance; good conductors fail to get a grip on the electricity so as to propel it effectively, while the grip of insulators is tremendous. Consequently it is probable that at any temperature at which electric resistance ceases, the Peltier effect will cease also.

Oltver Lodge.

\section{The Nature of the Emulsoid Golloid State.}

THE publication in the Transactions of the Chemical Society for December last of the latest of the extremely valuable and interesting investigations by Prof. J. W. McBain and his collaborators on soap solutions leads me to direct attention to a hypothesis as to the nature of the emulsoid colloid state. which I have briefly indicated in a technological paper on "Colloidal Fuels" (Journ. Ind. Eng. Chem., vol. xiii.. p. 37 , I92 I). The stabilising colloids used in these fuels belong to a class of bodies forming emulsoid sols and gels in non-aqueous systems, e.g. in hydrocarbon oils. The parallelism between certain such non-aqueous systems and aqueous emulsoids has struck many observers (notably M. Fischer) and caused considerable doubt as to the validity of the application of ionisation theories to the emulsoid colloids. Certainly it would appear that any theory of the

$$
\text { NO. 268I, VOL. IO7] }
$$

emulsoid systems must explain why sodium oleate forms sols and gels with water, whereas aluminium oleate does so with benzene.

The theory of micellar orientation supported by McBain appears to suffer in this respect, that the "micelle" postulated is alreaty a micro-colloid system, and the colloid properties are already present in the "micelle." A consistent theory of emulsoids must not only be in agreement both with the physical properties (viscosity of sols, gelation, elasticity of gels, hysteresis, etc.) and with the facts as to chemical constitution (polysaccharide character of starches and celluloses, polypeptide character of proteins, fatty acid salts for soaps, etc.), but it should also show the physical properties developing from the chemical composition and constitution. If colour and selective absorption flow from chemical composition and constitution, there appears no reason why cohesion and selective adsorption should not do so also. The suggestion which I put forward was stated as follows (loc. cit., p. 42) :-." Such gels-(heat reversible) not coagula - may be imagined as very tenuous web-works, or foams, the mesh or walls of which are very probably sub-molecular in dimensions, or the whole mass of the colloids forms one 'molecule' uniformly dispersed through and partially dissolving the solvent. By partially I mean that only part of the 'molecule' of the emulsoid is consolute with the solvent or dispergent, while the other part of it is insoluble, and its atoms tend to unite, forming a semi-rigid framework."

The hypothesis proposed does not regard micellar orientation (and attraction) as primarily responsible for emulsoid sols and gels, but rather sub-molecular (or transmolecular) orientation of definite atom-groups, entirely in the sense of the theory of molecular orientation due to structure proposed for surface and interfacial tension phenomena by W. B. Hardy (Proc. Ror. Soc., vol. Ixxxvi., A, p. 6ro, 1912), J. Langmuir (Journ. Amer. Chem. Soc., vol. xxxviii., p. 2221 , 1916; ibid., vol. xxxix., p. 1848, 1917), and W. Harkins (Journ. Amer. Chem. Soc., vol. xxxix., pp. 354 and 54I, $x_{917}$ ).

The genesis of a micelle, as plurimolecular unit of a colloid system, mav be regarded as a consequence of equilibrium, usually incomplete, between homochemical solution forces and heterochemical forces, the former tending to dissociate and decompose the chemical molecule, the latter resisting decomposition. In the case of proteins the most probable general type of linkage, according to $\mathrm{H}$. A. Plimmer ("Chemical Constitution of the Proteins," part ii., p. 2), is of the form

$$
\left.\mathrm{NH}_{2} \text {. CHR.CO.(NH.CHR.CO }\right)_{n} \text {. NH.CHR }
$$

where $n$ refers to the degree of polypeptide condensation and $\mathrm{R}$ is an alkyl or other substituent group. On the hypothesis suggested here we may, imperfectly, represent the redistribution of this in the presence of water for the polypeptide chain by

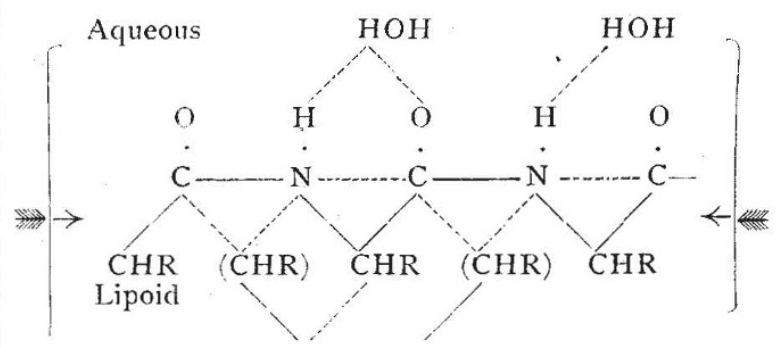

